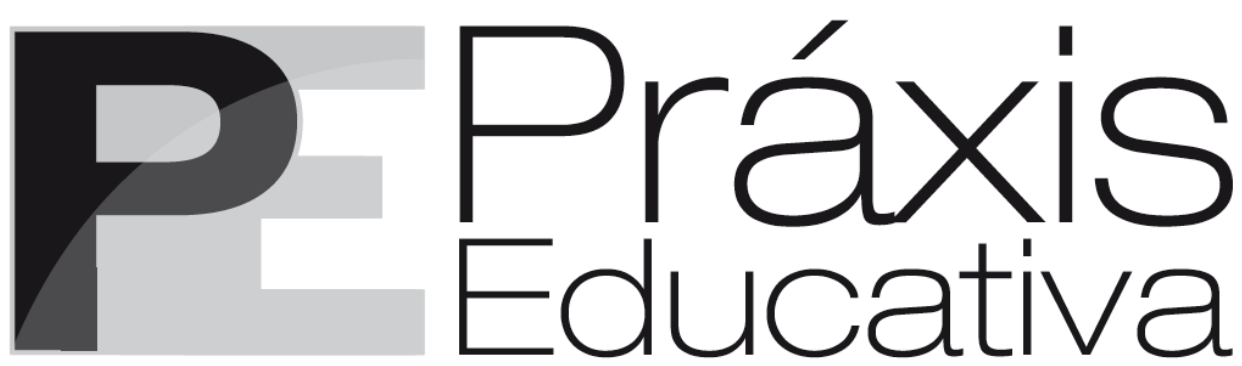

ISSN 1809-4031

elSSN 1809-4309

http://dx.doi.org/10.5212/PraxEduc.v.14n3.008

\title{
Análise das práticas pedagógicas de tutores para o incentivo do uso de estratégias de aprendizagem*
}

\section{Analysis of tutors' pedagogical practices to encourage the use of learning strategies}

\section{Análisis de las prácticas pedagógicas de tutores para el incentivo del uso de estrategias de aprendizaje}

\author{
Natália Moraes Góes** \\ Paula Mariza Zedu Alliprandini***
}

Resumo: Esta pesquisa teve o objetivo de identificar e analisar as práticas pedagógicas de tutores, na Educação a Distância $(\mathrm{EaD})$, para o incentivo do uso de estratégias de aprendizagem cognitivas, comportamentais e autorregulatórias pelos alunos. Para a coleta de dados, foi aplicado um questionário online, composto por sete questões que indagavam o tutor sobre as suas práticas pedagógicas diante de diversas situações do contexto escolar. Participaram da pesquisa 26 tutores, cujas respostas foram analisadas segundo os pressupostos da Análise de Conteúdo de Bardin (2004). Ao analisar as práticas pedagógicas dos tutores, verificou-se que eles indicaram incentivar com mais frequência as estratégias comportamentais. De modo geral, observou-se que as práticas pedagógicas dos tutores não estavam voltadas à promoção do uso de estratégias de aprendizagem. Os resultados da presente pesquisa apontam para a necessidade de novos estudos de intervenções, que visem ensinar as estratégias de aprendizagem para tutores da EaD.

Palavras-chave: Tutor. Educação a distância. Estratégias de aprendizagem.

Abstract: This research aimed at identifying and analyzing tutors' pedagogical practices, in Distance Learning, in order to encourage the use of cognitive, behavioral and self-regulatory learning strategies by the students. For data collection, an online survey was applied, composed by 7 questions which asked the tutor about his/her pedagogical practices in face of several situations in the school context. Twenty-six tutors took part in the survey and the answers were evaluated according to Bardin's (2004) Content

\footnotetext{
* A primeira autora agradece a Coordenação de Aperfeiçoamento Pessoal de Nível Superior (CAPES) pela concessão de bolsa de estudo. A segunda autora agradece ao Conselho Nacional de Desenvolvimento Tecnológico (CNPq) pelo financiamento da pesquisa (Processo no 4555092014-0).

** Mestre em Educação pela Universidade Estadual de Londrina. Doutoranda em Educação da Universidade Estadual de Campinas. E-mail: <nataliamoraesg@gmail.com>. ORCID: https://orcid.org/0000-0003-2557-0934

*** Docente adjunta do Departamento de Educação da Universidade Estadual de Londrina. Doutora em Psicobiologia pela Universidade de São Paulo. E-mail: <paulaalliprandini@gmail.com>. ORCID: https://orcid.org/0000-0003-4677-4258
} 
Analysis assumptions. When the tutors' pedagogical practices were analyzed, it was verified they indicated that behavioral strategies were encouraged more often. Generally, it was observed that the tutors' pedagogical practices were not aimed at promoting the use of learning strategies. The results of this research point to the need for new intervention studies that aim to teach learning strategies to distance learning tutors.

Keywords: Tutor. Distance learning. Learning strategies.

Resumen: Esta investigación tuvo el objetivo de identificar y analizar las prácticas pedagógicas de tutores, en la Educación a Distancia (EaD), para el incentivo del uso de estrategias de aprendizaje cognitivas, comportamentales y autorregulatorias por los alumnos. Para la recolección de datos, se aplicó una encuesta on-line, compuesta por siete preguntas que indagaban al tutor sobre sus prácticas pedagógicas ante diversas situaciones del contexto escolar. Participaron de la investigación 26 tutores, cuyas respuestas fueron analizadas según los supuestos del Análisis de Contenido de Bardin (2004). Al analizar las prácticas pedagógicas de los tutores, se verificó que ellos indicaron incentivar con más frecuencia las estrategias comportamentales. De modo general, se observó que las prácticas pedagógicas de los tutores no estaban direccionadas a la promoción del uso de estrategias de aprendizaje. Los resultados de la presente investigación apuntan para la necesidad de nuevos estudios de intervenciones que busquen enseñar las estrategias de aprendizaje para tutores de $\mathrm{EaD}$.

Palabras clave: Tutor. Educación a distancia. Estrategias de aprendizaje.

\section{Introdução}

De acordo com o referencial teórico da Psicologia Cognitiva/Teoria do Processamento da Informação, o funcionamento da mente humana assemelha-se ao de um computador (BZUNECK, 2010). Tal perspectiva assume a existência de um processador central, que é capaz de planejar e de controlar as atividades intelectuais. As dificuldades de aprendizagem, nessa linha teórica, estariam relacionadas à ausência de planejamento e de controle dos processos cognitivos, necessários para cada tarefa específica a ser realizada (BORUCHOVITCH, 2012).

As dificuldades de aprendizagem assim como as diferenças individuais dos estudantes são alvos de pesquisa e de preocupação de pais e de professores há muitos anos. Distintas explicações para as diferenças individuais já surgiram; entre essas explicações, destacam-se: falta de habilidades dos estudantes, currículo distante da realidade dos estudantes, ausência de habilidades metacognitivas e, atualmente, ausência de habilidades autorregulatórias (BORUCHOVITCH, 2014; ZIMMERMAN, 2002).

A autorregulação da aprendizagem foi definida por Zimmerman (2013) como a habilidade de planejar, de monitorar e de regular os próprios processos cognitivos, comportamentais, metacognitivos, motivacionais e afetivos com a finalidade de atingir uma determinada meta educacional. Assim, estudantes autorregulados apresentam características distintas dos demais estudantes, entre elas se pode mencionar: são ativos com relação à própria aprendizagem, utilizam com propriedade estratégias de aprendizagem, persistem em seus esforços para atingir as metas que estabelecem, apresentam motivação voltada à autonomia e a crenças de autoeficácia positivas (SCHUNK; ZIMMERMAN, 1998; ZIMMERMAN, 1990, 2002).

Como indicado, uma das características de estudantes autorregulados é o uso consciente das estratégias de aprendizagem. Essas habilidades não são desenvolvidas de forma natural ou automática, como muitos acreditam. Por isso, faz-se necessário que sejam ensinadas e incentivadas pelos professores, independentemente do nível de escolarização em que os estudantes estão inseridos (BORUCHOVITCH, 2007, 2014; BORUCHOVITCH; MACHADO, 2017; DEMBO, 2001; DÖRRENBÄCHER; PERELS, 2016; STEINBACH; STOEGER, 2016).

Práxis Educativa, Ponta Grossa, v. 14, n. 3, p. 955-973, set./dez. 2019 Disponível em: <http://www.revistas2.uepg.br/index.php/praxiseducativa> 
$\mathrm{Na}$ literatura, são encontradas inúmeras classificações para o constructo estratégias de aprendizagem, como pode ser visto com mais detalhes em Boruchovitch (1999). A taxionomia mais utilizada é aquela que distingue as estratégias de aprendizagem em dois grupos, as cognitivas e as metacognitivas. As estratégias cognitivas referem-se a uma série de comportamentos, que influenciam o processo de aprendizagem, a fim de que a informação seja armazenada mais eficientemente. Já as estratégias metacognitivas dizem respeito aos procedimentos utilizados pelos estudantes para planejar, monitorar e regular o seu próprio pensamento (DEMBO; SELI, 2012; LEFRANÇOIS, 1988; PINTRICH, 2004).

Outra taxonomia bastante reconhecida pela literatura é a que classifica as estratégias de aprendizagem em cognitivas, comportamentais e autorregulatórias (WARR; ALLAN, 1998). As estratégias de aprendizagem cognitivas são compostas pelas estratégias de ensaio, de elaboração e de organização. As estratégias de ensaio referem-se à repetição mental da informação da mesma forma que ela foi apresentada. Exemplo de estratégias de ensaio: repetir a informação várias vezes oralmente ou por escrito. As estratégias de elaboração contemplam a reflexão sobre implicações e possíveis conexões entre o material aprendido e o conhecimento já existente na estrutura cognitiva do indivíduo. Exemplo de estratégia de elaboração: resumir o texto, criar e responder perguntas. Já as estratégias de organização consistem na identificação das ideias centrais do material e criação de esquemas mentais que agrupam e relacionam elementos que foram aprendidos, de modo que as informações se tornem mais significativas para o estudante. Exemplo de estratégia de organização: criar mapas conceituais dos conteúdos estudados.

As estratégias de aprendizagem comportamentais são compostas pelas estratégias de busca de ajuda interpessoal, busca de ajuda no material escrito e aplicação prática. A estratégia de busca de ajuda interpessoal refere-se à obtenção de auxílio de outras pessoas para tirar dúvidas sobre o material. Exemplo dessa estratégia: buscar ajuda de professores e de colegas para sanar possíveis dúvidas. A estratégia de busca por ajuda no material escrito consiste em buscar ajuda em materiais, que não envolvam contato social. Por exemplo: procurar em livros, periódicos e sites, materiais que auxiliem na compreensão do conteúdo. Já a estratégia de aplicação prática incide sobre o aprimoramento do conhecimento, por meio da aplicação prática do que foi aprendido. Exemplo dessa estratégia: tentar aprimorar o conhecimento ao aplicá-lo em situações cotidianas.

As estratégias de autorregulação da aprendizagem são formadas pelas estratégias de controle da emoção, controle da motivação e monitoramento da compreensão. A estratégia de controle da emoção consiste em estratégias utilizadas para controlar a ansiedade e a dispersão da concentração. Serve de exemplo a estratégia: repetir a si mesmo que tudo dará certo. A estratégia de controle da motivação compreende regular a motivação e a atenção, mesmo quando o interesse pela tarefa a ser aprendida é limitado. Um exemplo dessa estratégia é: aumentar os esforços para aprender, quando o assunto não é muito interessante. $O$ monitoramento da compreensão refere-se à avaliação do processo de aquisição da aprendizagem e a modificação do comportamento do indivíduo, quando necessário. Como exemplo dessa estratégia, é possível citar: revisar a matéria para ver o quanto já se sabe sobre o conteúdo (WARR; ALLAN, 1998).

Pesquisas revelam que estudantes, independentemente do nível escolar em que estão inseridos, passam a apresentar um melhor desempenho escolar ao serem ensinados e incentivados a utilizarem estratégias de aprendizagem (BORUCHOVITCH et al., 2006; BORUCHOVITCH; SANTOS, 2015; OLIVEIRA; BORUCHOVITCH; SANTOS, 2009; RIOS, 2005; ZIMMERMAN; MARTINEZ-PONS, 1986). Isso porque, ao utilizarem estratégias de aprendizagem com propriedade, eles diminuem suas dificuldades de aprender e aprendem a controlar os fatores, que interferem diretamente no seu desempenho escolar 
(BORUCHOVITCH; SANTOS, 2015). Ao desenvolverem essas habilidades, passarão de uma atitude de estudantes passivos para uma atitude mais autônoma frente ao ato de aprender, pois serão capazes de reconhecer as suas dificuldades e tomarão decisões assertivas frente às inúmeras situações comumente encontradas no processo de ensino e de aprendizagem.

Se no Ensino Superior presencial se espera que o estudante apresente uma aprendizagem autônoma, tendo em vista os anos anteriores de escolarização, no Ensino Superior a distância essa característica é fundamental entre os estudantes, por tratar-se de uma modalidade de ensino, que apresenta uma organização diferente da encontrada no ensino convencional. Entre essas características, ressalta-se: mais flexibilidade de tempo e espaço de estudo, prazos a serem cumpridos, participações em chats, fóruns de discussões e em bate-papo, além da exigência por uma aprendizagem colaborativa (ABADI; REHFELDT, 2016; ABBAD; CORREAA; MENESES, 2010; ALLIPRANDINI et al., 2017; GÓES; 2015; GÓES; ALLIPRANDINI, 2017; PAVESI; ALLIPRANDINI, 2015).

Nesse sentido, autores como Abbad, Corrêa e Meneses (2010), Boruchovitch (1999, 2014), Góes (2015) e Teixeira e Alliprandini (2013) afirmam que, quando se pretende formar indivíduos competentes, capazes de pensar sobre sua própria cognição e autônomos com relação ao que esses aprendem, o ensino e o incentivo para o uso de estratégias de aprendizagem se torna fundamental. Nesse sentido, a $\mathrm{EaD}$ requer uma postura diferente não só de quem aprende, mas também de quem ensina, nessa modalidade de ensino e aprendizagem (ABADI; REHFELDT, 2016).

Ao reconhecer a importância de ensinar e incentivar o uso de estratégias de aprendizagem, independentemente do nível escolar que o estudante esteja cursando, na modalidade a distância, o tutor seria o principal responsável por fortalecer essas habilidades entre os estudantes, tendo em vista que ele é o profissional mais próximo do aluno na EaD. Nesse sentido, o presente estudo teve como objetivo identificar e analisar as práticas pedagógicas de tutores, na Educação a Distância, para o incentivo do uso de estratégias de aprendizagem cognitivas, comportamentais e autorregulatórias pelos alunos.

\section{Método}

\section{Participantes}

Participaram da pesquisa 26 tutores de um curso de Pedagogia, ofertado a distância, por uma instituição pública localizada no Norte do Paraná. Destes, 20 (76,9\%) eram do sexo feminino e $6(23,1 \%)$, do sexo masculino, com idades que variavam de 26 a 58 anos. Os tutores indicaram, como formação mínima, a Graduação em licenciatura, prevalecendo a formação no curso de Pedagogia. Do total de participantes, 92,3\% afirmaram ter recebido formação para atuar como tutores, em cursos com carga horária máxima de 180 horas.

\section{Instrumento de coleta de dados}

Para a coleta de dados, foi utilizado um questionário, composto por sete questões abertas, aplicado com o objetivo de investigar se os participantes da pesquisa incentivavam seus alunos a utilizarem estratégias autorregulatórias, comportamentais e cognitivas, em diferentes situações relacionadas ao contexto escolar. 
Para verificar o incentivo ao uso das estratégias autorregulatórias, uma das situações apresentadas no questionário foi: "Quando os alunos se apresentavam angustiados, apreensivos e duvidosos de sua capacidade para realizar alguma tarefa ou, até mesmo, para finalizar o curso". A fim de investigar o incentivo do uso das estratégias comportamentais, os participantes foram questionados sobre o que eles faziam: "Quando os alunos não participavam de chats e listas de discussões e não trocavam informações entre eles". Já, para avaliar se os participantes incentivavam o uso de estratégias cognitivas, a seguinte situação foi apresentada: "Quando os alunos apresentavam dificuldades para aprender o conteúdo do curso".

\section{Procedimentos de coleta de dados}

Inicialmente, o projeto tramitou e foi aprovado pelo Comitê de Ética envolvendo Seres Humanos (CEP) da Universidade Estadual de Londrina, conforme Parecer n ${ }^{\circ}$ 071/2013.

Antes da aplicação do questionário, dez avaliadores realizaram a análise das questões/situações que o compuseram. Entre os avaliadores, dois eram professores do Ensino Superior, três eram alunas de Iniciação Científica e cinco eram tutoras com experiência na EaD, de no mínimo um ano.

Após a adequação do questionário, conforme as sugestões e as orientações dos avaliadores, um link da pesquisa foi criado, utilizando-se o recurso do Google Drive. O link foi encaminhado via e-mail para uma lista de tutores presenciais e a distância, disponibilizada pelo Núcleo de Educação a Distância (NEAD) da instituição pesquisada. O tutor, ao acessar o link da pesquisa, deparava-se inicialmente com o Termo de Consentimento Livre e Esclarecido (TCLE). Após ler e aceitar o convite para participar da pesquisa, de acordo com as suas condições, outra página era aberta com o questionário. A cada nova resposta, o relatório cedido pelo Google Drive era atualizado e disponibilizado via Microsoft Office Excel, o que facilitou a organização das respostas.

\section{Procedimentos de análise dos dados}

Os dados foram analisados com base na Análise de Conteúdo proposta por Bardin (2004). As categorias criadas pelas autoras, a partir das respostas dos participantes, foram analisadas por três avaliadores com experiências anteriores no referencial teórico adotado para a análise do questionário.

\section{Resultados e discussão}

Para a organização dos dados obtidos, em primeiro lugar, serão apresentadas as categorias e as subcategorias criadas a partir das respostas dos participantes da pesquisa, relativas a sua prática pedagógica, em situações em que eles deveriam incentivar o uso de estratégias autorregulatórias (Questões 1, 2 e 3); na sequência, as questões nas quais eles precisariam estimular o uso de estratégias comportamentais (Questões 4 e 5); e, por fim, as categorias e as subcategorias criadas a partir das respostas às questões em que eles poderiam incentivar o uso de estratégias cognitivas (Questões 6 e 7). As categorias e as subcategorias relativas às questões 1, 2, e 3 podem ser visualizadas na Tabela 1 . 
Análise das práticas pedagógicas de tutores para o incentivo do uso de estratégias de aprendizagem

Tabela 1 - Categorias e subcategorias criadas a partir das respostas dos tutores em relação a diferentes situações que exigem o uso de estratégias autorregulatórias

\begin{tabular}{|c|c|c|}
\hline \multicolumn{3}{|c|}{$\begin{array}{l}\text { Questão } 1 \text { - Quando os alunos se apresentavam angustiados, apreensivos e duvidosos de sua capacidade para } \\
\text { realizar alguma tarefa ou, até mesmo, para finalizar o curso. }\end{array}$} \\
\hline Categoria & $\begin{array}{l}\text { Apoio do tutor no controle da emoção para favorecer o desenvolvimento } \\
\text { das atividades do curso }\end{array}$ & $\%$ \\
\hline \multirow{4}{*}{ Subcategorias } & Encorajamento à persistência & 22,2 \\
\hline & Motivação, enaltecendo o potencial dos estudantes & 22,2 \\
\hline & Contato com os estudantes & 22,2 \\
\hline & Estímulo à leitura & 7,5 \\
\hline \multicolumn{2}{|c|}{ Respostas que refletiram a prática pedagógica do professor } & 74,1 \\
\hline \multicolumn{2}{|c|}{ Respostas consideradas vagas e/ou distorcidas } & 25,9 \\
\hline \multicolumn{3}{|c|}{ Questão 2 - Quando os alunos apresentavam pouco interesse em relação a algum(s) conteúdo(s) } \\
\hline Categoria & $\begin{array}{l}\text { Ações dos tutores diante do pouco interesse dos alunos em relação a algum } \\
\text { conteúdo }\end{array}$ & $\%$ \\
\hline \multirow{5}{*}{ Subcategorias } & $\begin{array}{l}\text { Conscientização quanto à importância do conteúdo para a formação e para a } \\
\text { prática de pedagogo }\end{array}$ & 25,9 \\
\hline & $\begin{array}{l}\text { Estabelecimento de relações entre o conteúdo do curso e as vivências dos } \\
\text { estudantes }\end{array}$ & 18,5 \\
\hline & Motivação dos estudantes & 18,5 \\
\hline & Incentivo ao uso de outras formas para se obter e explorar o conteúdo & 14,8 \\
\hline & Promoção da autorreflexão & 7,4 \\
\hline \multicolumn{2}{|c|}{ Respostas que refletiram a prática pedagógica do professor } & 85,1 \\
\hline \multicolumn{2}{|c|}{ Respostas consideradas vagas e/ou distorcidas } & 14,9 \\
\hline \multicolumn{3}{|c|}{ Questão 3 - Quando os alunos não identificavam em quais conteúdos apresentavam mais dificuldades } \\
\hline Categoria & $\begin{array}{l}\text { Ações dos tutores diante da dificuldade do aluno em identificar as próprias } \\
\text { dificuldades }\end{array}$ & $\%$ \\
\hline \multirow{4}{*}{ Subcategorias } & Oferecimento de feedback & 26,9 \\
\hline & Retomada do material do curso (exercícios, conteúdos e videoaulas) & 19,2 \\
\hline & Apoio interpessoal & 19,2 \\
\hline & Atuação direta no conteúdo & 7,8 \\
\hline \multicolumn{2}{|c|}{ Respostas que refletiram a prática pedagógica do professor } & 73,1 \\
\hline \multicolumn{2}{|c|}{ Respostas consideradas vagas e/ou distorcidas } & 26,9 \\
\hline
\end{tabular}

Fonte: Organizada pelas autoras a partir dos dados da pesquisa.

Ao analisar a questão: "Quando os alunos se apresentavam angustiados, apreensivos e duvidosos de sua capacidade para realizar alguma tarefa ou, até mesmo, para finalizar o curso", verificou-se que apenas 74,1\% dos participantes indicaram o que faziam frente à situação, e $25,9 \%$ apresentaram respostas vagas e/ou distorcidas. Vale ressaltar que foram consideradas respostas vagas e/ou distorcidas todas aquelas que não indicaram a prática do professor diante da situação apresentada nas questões; por isso, essas respostas não serão apresentadas por não atenderem ao objetivo do presente estudo.

Esperava-se, na Questão 1, que os participantes incentivassem os alunos a se manterem calmos, mesmo diante de situações difíceis, que ensinassem aos estudantes falas internas para o controle da emoção e os ajudassem a lidar com a situação. No entanto, os participantes 
indicaram: encorajar os estudantes a persistirem (22,2\%); motivar, enaltecendo o potencial dos estudantes $(22,2 \%)$; manter contato com os estudantes $(22,2 \%)$; e estimular a leitura $(7,5 \%)$.

Os participantes diante de situações, nas quais os estudantes demonstravam descontrole emocional, buscaram, com mais frequência, encorajar os estudantes a persistirem $(22,2 \%)$ e motivá-los $(22,2 \%)$, de modo a elevar a autoestima, como pode ser visualizado no trecho que segue:

Tentava motivá-los com palavras de incentivo, de modo a elevar a autoestima e questionava qual era a dúvida para intervenção precisa, como: esclarecimento da atividade, envio de bibliografias úteis e feedback constante, quando o aluno tinha condições de enviar o trabalho antecipadamente. (P13).

Moore e Kearsley (2007) ressaltam que um dos fatores essenciais para o sucesso na EaD é a quantidade e a qualidade do diálogo entre alunos e tutores. $\mathrm{Na}$ fala destacada, bem como nas atitudes assumidas pelos participantes diante da situação apresentada, observa-se o esforço em manter o diálogo com os seus alunos, ação assumida por $22,2 \%$ dos participantes, não apenas no sentido de que eles cumprissem as atividades do curso, mas também mostrando o quanto são capazes e trabalhando com a motivação de cada um. Essas ações demonstram que os participantes compreendem a importância do seu papel e do seu incentivo para a aprendizagem dos estudantes e para a conclusão do curso.

Por fim, 7,5\% apontaram como uma das ações diante do descontrole emocional dos estudantes o estímulo à leitura, para que, ao lerem e estudarem mais, os estudantes pudessem se sentir mais preparados e afastassem os sentimentos que os afligiam diante da aprendizagem.

Quando o aluno apresenta controle emocional diante de situações que oferecem resultados diferentes do esperado por ele, pode-se dizer que ele desenvolveu capacidades autorregulatórias. Entende-se por habilidades autorregulatórias, sumariamente, a aptidão dos alunos em controlarem os processos cognitivos, a motivação, as emoções e o comportamento (BORUCHOVITCH, 2014). Bortoletto e Boruchovitch (2013) identificaram que estudantes, que sabem controlar suas emoções apresentam melhor desempenho escolar, o que denota a importância do uso dessas estratégias.

Embora os participantes demonstrem atitudes que incentivem os estudantes a permanecerem na tarefa, mesmo diante de situações difíceis, as respostas evidenciaram que eles não agem no sentido de ensinar e de promover o uso das estratégias de controle da emoção, uma vez que atuam de forma pontual, buscam apenas elevar a autoestima, motivar os estudantes e manter o contato com eles para que realizem as atividades, mas não evidenciam iniciativas para a promoção da autorregulação da aprendizagem.

A questão 2: "Quando os alunos apresentavam pouco interesse em relação a algum(s) conteúdo(s)" requeria que os participantes utilizassem estratégias autorregulatórias de controle da motivação. Verificou-se que $85,1 \%$ dos participantes indicaram algumas práticas pedagógicas utilizadas na situação proposta, e 14,9\% responderam de forma vaga e/ou distorcida.

Entre os participantes que relataram suas práticas pedagógicas (85,1\%), 25,9\% buscaram conscientizar os alunos sobre a importância do conteúdo para a formação e para a prática, de pedagogos; $18,5 \%$ indicaram estabelecer relações entre o conteúdo do curso e as vivências dos alunos; $18,5 \%$ motivaram os alunos; $14,8 \%$ apontaram incentivar outras formas de obter-se e explorar o conteúdo; e 7,4\% promoveram a autorreflexão.

Práxis Educativa, Ponta Grossa, v. 14, n. 3, p. 955-973, set./dez. 2019 Disponível em: <http://www.revistas2.uepg.br/index.php/praxiseducativa $>$ 
Análise das práticas pedagógicas de tutores para o incentivo do uso de estratégias de aprendizagem

Conscientizar os alunos sobre a importância do conteúdo para a formação e para a prática, em sala de aula, esforçando-se também para promover a autonomia nos estudos, capacidade imprescindível para acompanhar um curso a distância (ABADI; REHFELDT, 2016), foi uma das práticas pedagógicas apontadas por $25,9 \%$ dos participantes, exemplificada pela fala a seguir:

Normalmente, isso [desinteresse] ocorre quando o aluno acredita que o conteúdo é desnecessário, mas quando relacionado com a prática diária, ele começa a entender sua relevância, ainda que seja uma área que ele não goste muito. (P15).

Um exemplo em que os participantes demonstraram a preocupação em contextualizar os conteúdos, atribuindo a eles a importância para a prática, pode ser visto na sequência:

Apontar alguns tópicos relevantes e contextualizados com o cotidiano, de modo a instigar o aluno a saber mais sobre o conteúdo. (P6).

$\mathrm{Na}$ fala do Participante 6, é possível observar que ele não só se preocupou em aumentar o interesse do aluno, pelo conteúdo, por meio da sua relação com situações cotidianas, mas buscou, também, aproximá-lo de suas vivências para instigá-lo a buscar mais conhecimento sobre o assunto, incentivando-o à prática da pesquisa.

Além da prática pedagógica de conscientizar quanto a importância dos conteúdos para a formação e para a atuação, na qualidade de professores, os participantes indicaram estabelecer relações entre o conteúdo do curso e as vivências dos alunos (18,5\%), quando estes se mostravam desinteressados em relação aos conteúdos. Essas estratégias podem ser classificadas, de acordo com a literatura, por estratégias de regulação da motivação, mais especificamente, como indicam Paulino e Silva (2012) e Wolters e Benzon (2013), estratégias de regulação do valor. Estas consistem em tornar o material a ser aprendido mais útil, interessante ou importante para aprender. Ainda que os participantes utilizem essas estratégias com seus alunos, não há em suas ações a intenção de ensinar maneiras de controlar a motivação; pelo contrário, os participantes agiram como motivadores externos, o que indica que, em uma próxima situação, provavelmente os estudantes irão apresentar os mesmos comportamentos e não saberão o que fazer para modificá-lo. Além disso, esses resultados oferecem indícios de que os participantes do presente estudo desconhecem as estratégias de regulação da motivação e que estas podem ser ensinadas.

Os participantes informaram motivar os estudantes (18,5\%) e incentivá-los a estudar mais, oferecendo-lhes conselhos e mantendo contato constante. Mais uma vez, nota-se, assim como visto anteriormente, que os participantes agiram como motivadores externos. A prática pedagógica de motivar os estudantes é excelente; no entanto, se os participantes, concomitantemente desenvolvessem a metacognição para que os alunos pudessem compreender que eles podem controlar a própria motivação, os ganhos seriam maiores e em longo prazo. Os participantes também relataram que buscaram outras formas de obter o conteúdo $(14,8 \%$ ) e, quando assim agiam, procuravam promover a interação e a troca de informações entre os estudantes.

Em meio às práticas pedagógicas indicadas pelos participantes, verificou-se que 7,4\% buscaram promover a autorreflexão. A autorreflexão é de suma importância para a aprendizagem, pois é um dos meios para o desenvolvimento das capacidades metacognitivas. Dembo (2001), Bembenutty (2007) e Boruchovitch e Machado (2017) alertam quanto à necessidade e à eficácia da utilização de práticas autorreflexivas na formação do docente, para que tenham um processo de ensino e de aprendizagem mais eficaz e voltado ao fortalecimento das habilidades autorregulatórias. Entre os participantes, que agiram no sentido de promover a autorreflexão, destaca-se que eles buscaram direcionar os estudantes a relembrar do porquê de estarem

Práxis Educativa, Ponta Grossa, v. 14, n. 3, p. 955-973, set./dez. 2019 Disponível em: <http://www.revistas2.uepg.br/index.php/praxiseducativa> 
estudando, para que, a partir de suas reflexões, pudessem monitorar seu interesse e sua aprendizagem e criassem mecanismos para se autorregularem. Essa prática pedagógica, assumida por alguns participantes, indica que eles buscaram incentivar os alunos a utilizarem estratégias metacognitivas - nesse caso, a estratégia de regulação do comportamento (BORUCHOVITCH, 2007).

Quando o aluno consegue manter a motivação diante de conteúdos que não despertam grande interesse, pode-se afirmar que ele desenvolveu estratégias autorregulatórias de controle da motivação (PAULINO; SILVA, 2012; WOLTERS, 1999, WOLTERS; BENZON, 2013). Por meio das respostas dos participantes, verificou-se que ainda que eles tenham demonstrado utilizar tais estratégias, eles não agiram com a intenção de ensinar seus alunos como utilizá-las.

$\mathrm{Na}$ questão 3, a situação apresentada ansiava que os participantes estimulassem o uso da estratégia autorregulatória de monitoramento da compreensão: "Quando os alunos não identificam em quais conteúdos apresentam maior dificuldade". Na Tabela 1, é possível observar que: $73,1 \%$ dos participantes indicaram práticas pedagógicas frente a essa situação, e 26,9\% das respostas foram consideradas vagas e/ou distorcidas.

Entre os $73,1 \%$ de participantes que indicaram suas práticas pedagógicas, 26,9\% ofereceram feedback; $19,2 \%$ buscaram retomar o material do curso; $19,2 \%$ sugeriram que os alunos buscassem apoio interpessoal; e 7,8\% atuaram diretamente no conteúdo. Diante do objetivo de levar o aluno a monitorar a própria compreensão, esperava-se que os participantes incentivassem a revisão da matéria e ensinassem a verificar a própria aprendizagem, por meio de teste e de criação de perguntas; que ensinassem, desse modo, estratégias para o monitoramento da aprendizagem.

Com relação a essa questão, oferecer feedback aos alunos sobre suas dificuldades por meio de provas e de correção de trabalhos foi a resposta de $26,9 \%$ dos participantes, conforme o trecho destacado:

Os alunos tinham clareza dos conteúdos que tinham dificuldades, exceto quando eram surpreendidos pelas avaliações, achando que estudaram bastante e não foram tão bem quanto imaginavam. (P10).

A fala do Participante 10 demonstra que os alunos, em algumas situações, só tiveram clareza de que estavam com dificuldades em relação aos conteúdos quando foram surpreendidos com notas baixas nas provas. Esse cenário é extremamente preocupante, pois, como indicado na fala destacada, mesmo depois de realizarem os exercícios sobre o assunto e estudar para as provas, os alunos não conseguiam identificar suas dificuldades. Esse resultado demonstra que os alunos não utilizam estratégias de monitoramento da compreensão ou, se utilizavam, o faziam de forma equivocada, não apresentando um julgamento coerente com a sua aprendizagem.

A prática pedagógica de retomar os materiais do curso foi apontada por 19,2\% dos participantes. O trecho a seguir exemplifica essa prática:

As orientações eram dadas no sentido de rever as vídeoaulas, rever os conteúdos e estarem atentos às explicações dadas em momentos presenciais. (P5).

Entre os participantes, 19,2\% relataram que buscaram estabelecer relações próximas com os alunos, ofereceram apoio para tirar dúvidas e aconselharam os estudantes a buscarem por apoio interpessoal com outros colegas de curso e formarem grupos de estudo. Atuar diretamente no conteúdo foi indicado por $7,8 \%$ dos participantes, que buscaram ressaltar tópicos essenciais de cada disciplina e incentivaram os alunos a lerem o conteúdo para que identificassem suas 
Análise das práticas pedagógicas de tutores para o incentivo do uso de estratégias de aprendizagem

dificuldades. Ao analisar a atitude descrita, constata-se que, em um primeiro momento, os participantes buscaram auxiliar os alunos, ressaltando os tópicos essenciais da disciplina; em um segundo momento, eles incentivaram a leitura para que pudessem chegar as suas próprias reflexões e identificar suas dúvidas, desenvolvendo, desse modo, uma atitude mais autônoma diante da própria aprendizagem.

As estratégias autorregulatórias de monitoramento da compreensão são importantes e eficazes, quando utilizadas pelos alunos para avaliar sua própria aprendizagem. Isso porque, quando os estudantes monitoram a própria compreensão, eles são capazes de perceber o que estão aprendendo, o que está difícil, o que precisam melhorar, e, a partir desse julgamento, gerado pelo monitoramento, eles são capazes de regular a própria aprendizagem, utilizando estratégias mais adequadas para compreender e realizar a tarefa. Caso agissem dessa forma, dificilmente os estudantes seriam surpreendidos com feedbacks diferentes do esperado, porque eles já teriam consciência, previamente, sobre a própria compreensão e aprendizagem (DEMBO; SELI, 2012; ZAMPIERI; SCHELINI, 2013).

A partir das respostas dos participantes, verificou-se que eles não têm por hábito incentivar seus estudantes a utilizarem estratégias de avaliação da própria aprendizagem, pois agiram de forma mais geral, estimulando-os a reverem todo o conteúdo, sem identificar, de fato, suas dificuldades. A prática pedagógica de oferecer feedback aos alunos, ressaltando os pontos em que eles apresentavam dificuldades, foi uma estratégia boa, no entanto, as dificuldades foram identificadas pelos participantes e não pelos alunos. Os resultados evidenciam que os participantes ainda não utilizam, em suas práticas pedagógicas, ações que estimulam a capacidade autorregulatória de refletir e de regular sobre a própria compreensão.

$\mathrm{Na}$ sequência, a Tabela 2 apresenta as categorias e as subcategorias obtidas a partir das respostas dos participantes às diversas situações, em que se esperava que os estudantes utilizassem estratégias comportamentais.

Tabela 2 - Categorias e subcategorias criadas a partir das respostas dos tutores relativas às diferentes situações que exigem o uso de estratégias comportamentais

\begin{tabular}{|c|c|c|}
\hline \multicolumn{3}{|c|}{ Questão 4 - Quando os alunos não participavam de chats e listas de discussões e não trocavam informações entre el } \\
\hline Categoria & Ações dos tutores diante da não utilização das ferramentas disponíveis no AVA & $\%$ \\
\hline \multirow[t]{2}{*}{ Subcategorias } & $\begin{array}{l}\text { Estímulo à participação e à troca de informações, ressaltando a importância e a } \\
\text { obrigatoriedade do uso das ferramentas disponíveis no AVA }\end{array}$ & 42,9 \\
\hline & Contato com o aluno & 17,9 \\
\hline \multicolumn{2}{|c|}{ Respostas que refletiram a prática pedagógica do professor } & 60,8 \\
\hline \multicolumn{2}{|c|}{ Respostas consideradas vagas e/ou distorcidas } & 39,2 \\
\hline \multicolumn{3}{|c|}{$\begin{array}{l}\text { Questão } 5 \text { - Quando os alunos demonstravam não ter compreendido o texto-base disponibilizado pela } \\
\text { disciplina/atividade e/ou não apresentavam interesse em ampliar seus conhecimentos }\end{array}$} \\
\hline Categoria & $\begin{array}{l}\text { Ações dos tutores para lidar com as dificuldades de aprendizagem dos alunos em } \\
\text { relação ao conteúdo }\end{array}$ & $\%$ \\
\hline \multirow{4}{*}{ Subcategorias } & Incentivo à busca por materiais adicionais & 33,3 \\
\hline & Apoio interpessoal aos alunos & 30,3 \\
\hline & Simplificação do conteúdo & 12,1 \\
\hline & Incentivo à utilização de recursos disponíveis na plataforma & 3,0 \\
\hline \multicolumn{2}{|c|}{ Respostas que refletiram a prática pedagógica do professor } & 78,7 \\
\hline \multicolumn{2}{|c|}{ Respostas consideradas vagas e/ou distorcidas } & 21,3 \\
\hline
\end{tabular}

Fonte: Organizada pelas autoras a partir dos dados da pesquisa.

Práxis Educativa, Ponta Grossa, v. 14, n. 3, p. 955-973, set./dez. 2019 Disponível em: <http://www.revistas2.uepg.br/index.php/praxiseducativa> 
Ao analisar a questão: "Quando os alunos não participavam de chats e listas de discussões e não trocavam informações entre eles...", situação em que se esperava que os participantes incentivassem o uso de estratégias comportamentais de busca por ajuda interpessoal entre os alunos, verificou-se que $60,8 \%$ dos participantes indicaram quais foram suas práticas pedagógicas frente à situação indicada na questão; enquanto $39,2 \%$ das respostas foram consideradas vagas e/ou distorcidas.

As práticas pedagógicas assumidas pelos professores revelaram que 42,9\% estimularam a participação e a troca de informações, ressaltando a importância e a obrigatoriedade do uso das ferramentas disponíveis no AVA, e 17,9\% buscaram entrar em contato com os alunos. Demonstrar a importância do uso das ferramentas disponíveis na plataforma para a aprendizagem $(42,9 \%)$ foi a ação mais indicada pelos participantes. Por meio da análise das respostas, foi possível constatar que os participantes não buscaram apenas instigar o uso dessas ferramentas por serem obrigatórias para o curso e por contarem como carga horária, eles foram além, tentaram conscientizar os alunos sobre a importância do uso das ferramentas para a aprendizagem e para a troca de conhecimentos, como pode ser visualizado no relato a seguir:

Era preciso passar clareza aos alunos sobre o ambiente virtual de aprendizagem, de forma que entendessem que a participação nas discussões, virtualmente, se fazia uma ferramenta de aprendizagem e troca de experiências e também parte da carga horária exigida pelo curso. (P20).

Os participantes, ao buscarem entrar em contato com os alunos $(17,9 \%)$, utilizaram distintos meios para isso, tais como: enviaram e-mail, telefonaram, entraram em contato na plataforma, entre outras formas. Essa prática pedagógica condiz com o que propõem Bicalho e Oliveira (2012) e Santos (2014) sobre a importância do estímulo do tutor para a participação dos alunos em chats e listas de discussões. Quando o tutor interage com o aluno, este se sente mais motivado a participar, pois tem a certeza de que existe um interlocutor do outro lado para ouvir e prestar assistência (BICALHO; OLIVEIRA, 2012; SANTOS, 2014).

O uso de estratégias de aprendizagem comportamental subentende uma atitude proativa do estudante em solicitar ajudar (BORUCHOVITCH, 1999; ZERBINI; ABBAD, 2005). Com base nas respostas foi possível constatar que grande parte dos participantes buscou incentivar a troca de informações entre alunos e entre alunos e tutores, principalmente por meio das ferramentas disponíveis na plataforma.

A questão: "Quando os alunos demonstravam não ter compreendido o texto-base disponibilizado pela disciplina/atividade e/ou não apresentavam interesse em ampliar seus conhecimentos...", trata de uma situação em que se espera o uso de estratégias de aprendizagem comportamentais de busca por ajuda ao material didático. As respostas dos participantes evidenciaram que 78,7\% apontaram suas práticas pedagógicas diante da situação indicada, e $21,3 \%$ das respostas foram consideradas vagas e/ou distorcidas.

Diante da situação, 78,7\% dos participantes indicaram suas práticas pedagógicas, entre elas: $33,3 \%$ incentivaram a busca por materiais adicionais; 30,3\% ofereceram e estimularam apoio interpessoal aos alunos; 12,1\% buscaram simplificar o conteúdo; e 3,0\% incitaram a utilização dos recursos disponíveis na plataforma. Frente às respostas dos participantes, foi possível verificar que 33,3\% indicaram incentivar os alunos a buscarem por materiais adicionais, realizando-se, assim, o que se esperava que o tutor fizesse diante de uma situação como essa. Verificou-se, a partir dessas respostas, que os participantes incentivaram a pesquisa e a prática da investigação. 
Análise das práticas pedagógicas de tutores para o incentivo do uso de estratégias de aprendizagem

Oferecer apoio interpessoal foi uma das práticas pedagógicas indicadas por 30,3\% dos participantes. Para isso, eles incentivaram a realização de grupos de estudo e a discussão em grupo. Diante da dificuldade de compreensão do conteúdo, $12,1 \%$ buscaram simplificar o conteúdo para os alunos, fazendo resumos e desenvolvendo quadros explicativos para facilitar a assimilação. Ao agirem dessa forma, esses participantes diminuíram as possibilidades de os alunos agirem no texto, de forma independente, buscarem a compreensão do conteúdo e, também, desenvolverem uma aprendizagem significativa. Por fim, 3,0\% dos participantes incentivaram os estudantes a utilizarem os recursos disponíveis na plataforma.

A estratégia comportamental de busca de ajuda no material didático é um importante procedimento que pode ser utilizado pelo tutor, quando o aluno demonstra dificuldades na compreensão de um determinado texto. Diante disso, 33,3\% dos participantes incentivaram a busca por materiais adicionais; por outro lado, 30,3\% dos participantes estimularam os alunos a buscarem apoio interpessoal. Assim, parte dos participantes buscou incentivar a pesquisa, a fim de que, em situações posteriores, os alunos agissem de forma autônoma e não ficassem esperando pelo tutor, já outra parte dos participantes estimulou o apoio interpessoal, o que não garante que o aluno agirá de forma autônoma em outras situações semelhantes.

A seguir, a Tabela 3 apresenta as categorias e as subcategorias obtidas a partir da análise das respostas das questões que suscitavam o uso de estratégias cognitivas.

Tabela 3 - Categorias e subcategorias criadas a partir das respostas dos tutores relativas às diferentes situações que exigem o uso de estratégias cognitivas

\begin{tabular}{|c|c|c|}
\hline \multicolumn{3}{|c|}{ Questão 6 - Quando os alunos apresentavam dificuldades em aprender o conteúdo do curso } \\
\hline Categoria & $\begin{array}{l}\text { Ações desempenhadas pelos tutores para lidar com as dificuldades de } \\
\text { aprendizagem dos alunos em relação aos conteúdos }\end{array}$ & $\%$ \\
\hline \multirow{5}{*}{ Subcategorias } & Incentivo à busca por materiais adicionais & 23,5 \\
\hline & Incentivo à busca por ajuda interpessoal & 17,6 \\
\hline & Questionamentos e esclarecimento de dúvidas & 17,6 \\
\hline & Momentos de reflexão e leitura com os alunos & 8,8 \\
\hline & Simplificação do conteúdo & 8,8 \\
\hline \multicolumn{2}{|c|}{ Respostas que refletiram a prática pedagógica do professor } & 76,3 \\
\hline \multicolumn{2}{|c|}{ Respostas consideradas vagas e/ou distorcidas } & 23,7 \\
\hline \multicolumn{3}{|c|}{ Questão 7 - Quando os alunos não apresentavam uma aprendizagem significativa } \\
\hline Categoria & $\begin{array}{l}\text { Ações dos tutores quando os alunos não apresentavam uma aprendizagem } \\
\text { significativa }\end{array}$ & $\%$ \\
\hline \multirow{6}{*}{ Subcategorias } & Incentivo aos estudos e à releitura do material do curso & 14,7 \\
\hline & Incentivo à busca por materiais adicionais & 8,8 \\
\hline & Relação dos conteúdos com a prática & 8,8 \\
\hline & Incentivo à autorreflexão & 8,8 \\
\hline & Compreensão das dificuldades de cada aluno & 8,8 \\
\hline & Revisão dos conteúdos & 5,9 \\
\hline \multicolumn{2}{|c|}{ Respostas que refletiram a prática pedagógica do professor } & 55,8 \\
\hline \multicolumn{2}{|c|}{ Respostas consideradas vagas e/ou distorcidas } & 44,2 \\
\hline
\end{tabular}

Fonte: Organizada pelas autoras a partir dos dados da pesquisa. 
A questão 6 indagava as práticas pedagógicas dos participantes: "Quando os alunos apresentavam dificuldades em aprender o conteúdo do curso...". Essa questão suscitava a necessidade de os alunos utilizarem estratégias cognitivas de repetição e de organização. De acordo com a Tabela 3,76,3\% dos participantes indicaram quais foram suas práticas pedagógicas diante da situação elencada, já $23,7 \%$ das respostas foram consideradas vagas e/ou distorcidas.

Com relação aos 76,3\% de participantes que indicaram suas práticas pedagógicas: 23,5\% incentivaram a busca por materiais adicionais; $17,6 \%$ estimularam a busca por ajuda interpessoal; $17,6 \%$ realizaram questionamentos e esclareceram dúvidas; $8,8 \%$ promoveram momentos de reflexão e leitura com os alunos; e 8,8\% buscaram simplificar o conteúdo.

Como forma de suprir as dificuldades dos alunos, 23,5\% dos participantes incentivaram a busca por materiais adicionais. Quando assim agiram, tinham por objetivo levar os alunos a construírem seu próprio conhecimento a partir da reflexão, de modo a promover a autonomia. O incentivo à busca por ajuda interpessoal foi também indicado pelos participantes $(17,6 \%)$ como uma forma de instigar a interação entre os membros da $\mathrm{EaD}$, como pode ser visto no relato apresentado a seguir:

Eram orientados a se reunirem em grupos para revisar os conteúdos e discutir as dúvidas ou a entrar em contato com os professores responsáveis pela disciplina para tirar suas dúvidas. (P19).

As respostas dos participantes indicam que eles agiram no sentido de promover a aprendizagem colaborativa, pois incentivaram a criação de grupos de estudo e a troca de conhecimento entre os alunos. Prática pedagógica distinta foi apontada por 17,6\% dos participantes, ao informarem que faziam perguntas aos alunos e, assim, esclareciam dúvidas e geravam a reflexão dos alunos sobre a própria aprendizagem. Outros professores $(8,8 \%)$ agiram focando, exclusivamente, em incentivar a reflexão para sanar as dúvidas dos estudantes, como pode ser verificado no trecho a seguir.

Chamava para conversarmos nos horários que estava realizando o plantão. Durante esse momento, poderia dar uma atenção mais individual e realizar leituras com os alunos ou esclarecer como trabalhar com a plataforma Moodle. (P7).

O trecho destacado demonstra a atenção do participante, por meio de conversas com os alunos, com o objetivo de estar próximo e poder auxiliá-los em suas dúvidas, mesmo que virtualmente. Essa prática pedagógica, realizada com os alunos, demonstra o acolhimento que o participante conferia ao aluno, não o deixando solitário no processo de ensino e de aprendizagem.

Em situações como a apresentada na Questão 5, em que se espera que os alunos utilizem estratégias de repetição e de organização, as práticas pedagógicas dos professores deveriam estar voltadas a incentivar e a ensinar os alunos a fazerem anotações, a repetirem o conteúdo estudado mentalmente, fazerem desenhos, esquemas dos conteúdos e dos resumos; utilizar, dessa maneira, ferramentas que auxiliam no armazenamento da informação e posterior recuperação.

Como apresentado anteriormente, na Tabela 2, referente ao uso de estratégias comportamentais, ao verificar-se o incentivo ao uso de estratégias cognitivas, também se constatou que $8,8 \%$ dos participantes costumavam simplificar o conteúdo, como pode ser visto no trecho destacado: 
Análise das práticas pedagógicas de tutores para o incentivo do uso de estratégias de aprendizagem

Fazer alertas com recados e avisos para o aluno se organizar e buscar sua autonomia nos estudos. O papel do tutor é promover a proposta do curso, incentivar e motivar os conteúdos. Eu, percebendo a dificuldade com algum conteúdo, fiz resumo, quadros explicativos, tabelas, mostrando os conteúdos de forma mais simples. (P5).

A fala do Participante 5 ressalta, a princípio, a importância e a necessidade de se desenvolver, nos alunos, a autonomia nos estudos, fator essencial na EaD. No entanto, em vez de incentivar os alunos a utilizarem estratégias distintas para facilitar a assimilação dos conteúdos, quem realizou esse papel foi o próprio participante. Ao analisar a resposta do participante, observa-se um distanciamento entre a sua fala e a sua prática. Nessa situação, o incentivo à construção de mapas conceituais seria um excelente recurso, pois eles promovem reflexão, estabelecimento de relação entre os conceitos e a aprendizagem significativa, proposta por Ausubel (NOVAK; CAÑAS, 2010).

Ao analisar as respostas dos participantes sobre o incentivo ao uso de estratégias cognitivas de repetição e de organização, verificou-se que eles não buscaram estimular o uso de tais estratégias, pois optaram por estar próximo ao aluno e agir por eles, em situações em que a autonomia e o incentivo ao uso de estratégias cognitivas poderia ser estimulado.

$\mathrm{Na}$ situação aventada na questão 7, "Quando os alunos não apresentavam uma aprendizagem significativa...", esperava-se o uso de estratégias de aprendizagem cognitiva de elaboração. Verificou-se que 55,9\% dos participantes indicaram práticas pedagógicas realizadas diante de tal situação, e 44,2\% apresentaram respostas vagas e/ou distorcidas.

Entre os $55,9 \%$ de participantes que responderam à questão, $14,7 \%$ incentivaram o estudo e a releitura do material do curso; $8,8 \%$ estimularam a busca por materiais adicionais; $8,8 \%$ estabeleceram relações entre o conteúdo e a prática; $8,8 \%$ incentivaram a autorreflexão; $8,8 \%$ buscaram compreender as dificuldades de cada aluno, e 5,9\% revisaram o conteúdo. Diante da situação levantada, esperava-se que os participantes incentivassem os alunos a associarem os conteúdos novos aos já aprendidos anteriormente e as suas experiências anteriores e identificassem situações no dia a dia, em que esse conteúdo pudesse ser aplicado.

A partir das práticas pedagógicas elencadas, constatou-se que 14,7\% incentivaram o estudo e a releitura do material disponibilizado no curso. Ao agirem dessa forma, possibilitaram que os alunos refletissem, novamente, sobre o conteúdo e repensassem sua aprendizagem, o que poderia levá-los a retomar os pontos não compreendidos.

Outra vez, os participantes incentivaram: a busca por materiais adicionais $(8,8 \%)$, para que, assim, a aprendizagem significativa se efetivasse; e o desenvolvimento de relações entre os conteúdos estudados e a prática dos alunos $(8,8 \%)$, o que pode ser constatado no trecho a seguir:

Buscava comentários que relacionassem a teoria com a prática para que pudessem vivenciar os conteúdos que estavam aprendendo. (P11).

Além de vivenciar os conteúdos que estão sendo aprendidos, Paixão e Ferro (2009) afirmam que é importante que os alunos deem significado a esses conteúdos, relacionando-os às suas experiências anteriores. No entanto, cabe esclarecer que a relação entre o conteúdo e a prática dos alunos era realizada pelo tutor e não pelo aluno, como pôde ser confirmado na resposta do Participante 11. É fundamental estimular o aluno a fazer suas próprias relações entre o conteúdo e suas experiências pedagógicas, visto ser mais significativo para a sua aprendizagem.

Incentivar a reflexão sobre a própria aprendizagem e compreender as dificuldades de cada aluno para poder intervir foram indicados por 8,8\% dos participantes. Para detectar as dificuldades dos alunos, os participantes informaram utilizar os recursos disponíveis na 
plataforma. Por fim, quando os alunos não apresentavam uma aprendizagem significativa, 5,9\% dos participantes indicaram retomar o conteúdo. A revisão dos conteúdos ocorria nos encontros presenciais, quando os participantes retomavam o conteúdo e apontavam o que era preciso melhorar.

Sobre o incentivo ao uso de estratégias de elaboração pelos participantes da pesquisa, pode-se afirmar que a prática pedagógica que suscitou sua utilização foi: criar relações entre os conteúdos estudados com a prática dos alunos e suas experiências anteriores. Entretanto, ao analisar as respostas, verificou-se que esse esforço era realizado pelos tutores e não pelos alunos, o que demonstra que não houve incentivo ao uso de estratégias de elaboração por parte dos participantes que compuseram este estudo.

\section{Considerações finais}

As análises dos resultados obtidos pela presente pesquisa indicaram que os participantes realizaram, em sua prática, as funções que lhes são atribuídas, de acordo com os Referenciais de Qualidade do Ensino Superior a Distância (BRASIL, 2007), que são: auxiliar os alunos em suas dúvidas, promover e incentivar o uso das ferramentas disponíveis na plataforma e manter contato com os alunos; no entanto, agir e atuar independentemente na aprendizagem foi pouco estimulado.

Quanto ao objetivo proposto, nesta pesquisa, os resultados permitiram verificar que, entre as intervenções realizadas pelos participantes, as estratégias comportamentais de busca de ajuda ao material didático e por ajuda interpessoal foram as mais incentivadas por eles. Sobre as estratégias autorregulatórias e cognitivas, as autoras observaram que os participantes parecem não incentivar o uso dessas estratégias, pois algumas práticas pedagógicas foram realizadas sem a intenção de ensiná-las e promover o uso, o que sugere que os participantes do presente estudo desconhecem os benefícios do uso de estratégias autorregulatórias e cognitivas para a aprendizagem e a importância do ensino e do incentivo do uso dessas estratégias.

As limitações deste estudo são reconhecidas, em especial, ao considerar que os dados foram analisados a partir do que foi relatado pelos participantes, o que pode gerar uma expectativa de resposta por parte deles. Sugere-se o desenvolvimento de novas pesquisas sobre a temática, como, por exemplo, o conhecimento das estratégias de aprendizagem por parte dos tutores. Além disso, recomenda-se a realização de intervenções com os tutores, para que estes possam receber formação sobre o constructo estratégias de aprendizagem e, assim, passem a incentivar o seu uso, visando a formação de alunos independentes e críticos com relação à própria aprendizagem.

\section{Referências}

ABBAD, G. da S.; CORRÊA, V. P.; MENESES, P. P. M. Avaliação de treinamentos a distância: relações entre estratégias de aprendizagem e satisfação com o treinamento. Revista de Administração Mackenzie, São Paulo, v. 11, n. 2, p. 43-67, mar./abr. 2010. DOI: http://dx.doi.org/10.1590/S1678-69712010000200003

ABADI, A. M.; REHFELDT, M. J. H. Autonomia para aprender: uma relação entre o fracasso e o sucesso dos alunos da Educação a Distância. Práxis Educativa, Ponta Grossa, v. 11, n. 2, p. 310-331, maio/ago. 2016. DOI: http://dx.doi.org/10.5212/PraxEduc.v.11i2.0001 
ALLIPRANDINI, P. M. Z. et al. The performance of tutors from a public institution and the encouragement for the use of learning strategies by students. American Journal of Educational Research, v. 5, p. 56-62, 2017. DOI: https://dx.doi.org/10.12691/education-5-1-9

BARDIN, L. Análise de conteúdo. 3. ed. Portugal: Edições 70, 2004.

BEMBENUTTY, H. Preservice teachers' motivational beliefs and self-regulation of learning. In: ANNUAL MEETING AMERICAN EDUCATIONAL RESEARCH ASSOCIATION, 1., 2007, Chicago. Anais... Chicago: American Educational Research Association, 2007.

BICALHO, R. N. de M.; OLIVEIRA, M. C. S. L. O processo dialógico de construção do conhecimento em fóruns de discussão. Interface Comunicação, Saúde e Educação, Botucatu, v. 16, n. 41, p. 469-483, jun. 2012. DOI: https://dx.doi.org/10.1590/S1414-32832012005000028

BORTOLETTO, D.; BORUCHOVITCH, E. Learning strategies and emotional regulation of pedagogy students. Paideia, Ribeirão Preto, v. 23, n. 55, p. 235-242, maio/ago. 2013. DOI: http://dx.doi.org/10.1590/1982-43272355201311

BORUCHOVITCH, E. Estratégias de aprendizagem e desempenho escolar: considerações para a prática educacional. Psicologia: Reflexão e Crítica, Porto Alegre, v. 12, n. 2, p. 361-376, 1999. DOI: http://dx.doi.org/10.1590/S0102-79721999000200008

BORUCHOVITCH, E. Aprender a aprender: proposta de intervenção em estratégias de aprendizagem. Educação Temática Digital, Campinas, v. 8, n. 2, p. 156-167, jun. 2007. DOI: https://doi.org/10.20396/etd.v8i2.651

BORUCHOVITCH, E. Dificuldades de aprendizagem, problemas motivacionais e estratégias de aprendizagem. In: SISTO, F. F. et al. (Orgs.). Dificuldades de aprendizagem no contexto psicopedagógico. 8. ed. Rio de Janeiro: Vozes, 2012. p. 40-59.

BORUCHOVITCH, E. Autorregulação da aprendizagem: contribuições da psicologia educacional para a formação de professores. Revista Quadrimestral da Associação Brasileira de Psicologia Escolar e Educacional, São Paulo, v. 18, n. 3, p. 401-409, set. 2014. DOI: http://dx.doi.org/10.1590/2175-3539/2014/0183759

BORUCHOVITCH, E. et al. Estudo preliminar para construção de uma escala de estratégias de aprendizagem infantil. Psicologia: Teoria e Pesquisa, Brasília, v. 22, n. 3, p. 297-304, set./dez. 2006. DOI: http://dx.doi.org/10.1590/S0102-37722006000300006

BORUCHOVITCH, E.; MACHADO, A. C. T. A. A autorregulação da aprendizagem na formação inicial e continuada de professores: como intervir para desenvolver?. In: POLYDORO, S. A. J. (Org.). Promoção da autorregulação da aprendizagem: contribuições da Teoria Social Cognitiva. Porto Alegre: Letra 1, 2017. p. 89-104.

BORUCHOVITCH, E.; SANTOS, A. A. A. Psychoimetric studies of the learning strategies scale for university students. Paideia, Ribeirão Preto, v. 25, n. 60, p. 19-27, jan./abr. 2015. DOI: http://dx.doi.org/10.1590/1982-43272560201504

BRASIL. Ministério da Educação. Referenciais de qualidade para Educação Superior a distância. Brasília, DF: MEC; SEED, 2007. 
BZUNECK, J. A. Aprendizagem por processamento da informação: uma visão construtivista. In: BORUCHOVITCH, E.; BZUNECK, J. A. (Orgs.). Aprendizagem processos psicológicos e o contexto social na escola. Rio de Janeiro: Vozes, 2010. p. 17-54.

DEMBO, M. Learning to teach is not enough: future teachers also need to learn to learn. Teacher Education Quarterly, v. 28, n. 4, p. 23-35, 2001.

DEMBO, M.; SELI, H. Motivation and learning strategies for college success: a focus on self-regulated learning. New York: Routledge, 2012.

DÖRRENBÄCHER, L., PERELS, F. More is more? Evaluation of interventions to foster self regulated learning in college. International Journal of Educational Research, v. 78, p. 50-65, 2016. DOI: https://doi.org/10.1016/j.ijer.2016.05.010

GÓES, N. M. Análise das estratégias de aprendizagem de alunos de um curso de pedagogia ofertado a distância e a atuação do tutor. 2015. 185 f. Dissertação (Mestrado em Educação) - Universidade Estadual de Londrina, Londrina, 2015.

GÓES, N. M.; ALLIPRANDINI, P. M. Z. Estratégias de aprendizagem de alunos de um curso de pedagogia a distância. Psicologia da Educação, São Paulo, v. 45, p. 57-66, 2017. DOI: http://dx.doi.org/10.5935/2175-3520.20170017

LEFRANÇOIS, G. Psychology for teaching. 6. ed. California: Wadsworth Publishing Company, 1988.

MOORE, M.; KEARSLEY, G. Educação a distância: uma visão integrada. São Paulo: Thomson, 2007.

NOVAK, J. D.; CANÃS, A. A teoria subjacente aos mapas conceituais e como elaborá-lo e usálo. Práxis Educativa, Ponta Grossa, v. 5, n. 1, p. 9-29, jan./jun. 2010. DOI: http://dx.doi.org/10.5212/PraxEduc.v.5i1.009029

OLIVEIRA, K. L.; BORUCHOVITCH, E.; SANTOS, A. A. A. Estratégias de aprendizagem e desempenho acadêmico: evidências de validade. Psicologia Teoria e Pesquisa, Brasília, v. 25, n. 4, p. 531-536, out/dez. 2009. DOI: http://dx.doi.org/10.1590/S0102-37722009000400008

PAIXÃO, M. S. S. L.; FERRO, M. G. D. F. A teoria da aprendizagem significativa de David Ausubel. In: CARVALHO, M. V. C.; MATOS, K. S. A. L. (Orgs.). Psicologia de educação: teorias do desenvolvimento e da aprendizagem em discussão. Fortaleza: UFC, 2009. p. 81-113.

PAULINO, P.; SILVA, A. L. Promover a regulação da motivação na aprendizagem. Cadernos de Educação, Pelotas, v. 42, n. 96, p. 96-118, 2012. DOI: http://dx.doi.org/10.15210/caduc.v0i42.2150

PAVESI, M. A.; ALLIPRANDINI, P. M. Z. Autorregulação da aprendizagem de alunos de cursos a distância em função do sexo. UNOPAR Científica Ciências Humanas e Educação, Londrina, v. 16, n. 2 p. 100-108, abr. 2015. DOI: http://dx.doi.org/10.17921/2447$\underline{8733.2015 \mathrm{v} 16 \mathrm{n} 2 \mathrm{p} 100-108}$ 
PINTRICH, P. R. A conceptual framework for assessing motivation and self-regulated learning in college students. Educational Psychology Review, v. 16, n. 4, p. 385-407, 2004. DOI: https://doi.org/10.1007/s10648-004-0006-x

RIOS, E. R. C. A intervenção por meio da instrução em estratégias de aprendizagem: contribuições para a produção de textos. 2005. 177 f. Tese (Doutorado em Educação) Universidade Estadual de Campinas, São Paulo, 2005.

SANTOS, G. L. Educação a distância na formação profissional continuada de professores da educação básica: analisando contratos e destratos didáticos, a partir de um estudo de caso. Educar em Revista, Curitiba, v. 1, n. 52, p. 275-290, abr./jun. 2014. DOI: http://dx.doi.org/10.1590/0104-4060.36096

SCHUNK, D.; ZIMMERMAN, B. Self-regulated learning: from teaching to self-reflective pratice. New York: The Guilford Press, 1998.

STEINBACH, J.; STOEGER, H. How primary school teachers' attitudes towards self-regulated learning (SRL) influence instructional behavior and training implementation in classrooms. Teaching and teacher education, v. 60, p. 256-269, 2016. DOI: https://doi.org/10.1016/j.tate.2016.08.017

TEIXEIRA, A. R.; ALLIPRANDINI, P. M. Z. Intervenção no uso de estratégias de aprendizagem diante de dificuldades de aprendizagem. Psicologia escolar e educacional, Maringá, v. 17, n. 2, p. 279-288, jul./dez. 2013. DOI: http://dx.doi.org/10.1590/S1413$\underline{85572013000200010}$

WARR, P.; ALLAN, C. Learning strategies and occupational training. International Review of Industrial and Organizational Psychology, v. 13, p. 83-121, 1998.

WOLTERS, C. A. The relation between high school students' motivational regulation and their use of learning strategies, effort, and classroom performance. Learning and Individual Differences, v. 3, n. 3, p. 281-299, 1999. DOI: https://doi.org/10.1016/S1041-6080(99)80004-1

WOLTERS, C. A.; BENZON, M. B. Assessing and predicting college students' use of strategies for the self-regulation of motivation. The Journal of Experimental Education, v. 81, n. 2, p. 199-221, fev. 2013. DOI: https://doi.org/10.1080/00220973.2012.699901

ZAMPIERI, M.; SCHELINI, P. W. O uso de medidas intelectuais na análise do monitoramento metacognitivo de crianças. Psicologia Teoria e Prática, Brasília, v. 29, n. 2, p. 81-89, 2013. DOI: http://dx.doi.org/10.1590/S0102-37722013000200007

ZERBINI, T.; ABBAD, G. S. Impacto de treinamento no trabalho via internet. RAEEletrônica, Brasília, v. 4, n. 2, jul./dez. 2005. DOI: http://dx.doi.org/10.1590/S1676$\underline{56482005000200001}$

ZIMMERMAN, B. J. Self-regulated learning and academic achievement: an overview. Education Psychologist, v. 25, n. 1, p. 3-17, 1990. DOI: http://dx.doi.org/10.1207/s15326985ep2501 2 
ZIMMERMAN, B. J. Becoming a self-regulated learner: an overview. Theory into practice, v. 41, n. 2, p. 64-70, 2002. DOI: https://doi.org/10.1207/s15430421tip4102 2

ZIMMERMAN, B. J. From cognitive modeling to self-regulation: a social cognitive career path. Educational Psychologist, v. 48, n. 3, p. 135-147, 2013. DOI: https://doi.org/10.1080/00461520.2013.794676

ZIMMERMAN, B. J.; MARTINEZ-PONS, M. Development of a structured interview for assessing student use of self-regulated learning strategies. American Educational Research Journal, v. 23, n. 4, p. 614-628, 1986. DOI: https://doi.org/10.3102\%2F00028312023004614

Recebido em 14/05/2019

Versão corrigida recebida em 16/07/2019

Aceito em 20/07/2019

Publicado online em 25/07/2019 